\title{
Megaloencephalic leukoencephalopathy with subcortical cyst formation (van der Knaap disease)
}

\author{
Ajay Malhotra $\cdot$ Per-Lennart Westesson
}

Received: 04 September 2009 /Revised: 28 October 2009/Accepted: 12 November 2009/Published online: 18 December 2009

(C) Springer-Verlag 2009

A child born at full term developed macrocephaly in infancy with regression of motor skills and cerebellar ataxia starting at age 3 that progressively worsened. Axial T2 weighted (T2-W) MRI (Fig. 1) shows diffuse white matter hyperintensity involving the subcortical fibers as well as sparing of the basal ganglia as thalami. Subcortical cyst formation is seen in the anterior temporal region on the sagittal T2-W image (Fig. 2, arrow). No contrast enhancement was noted.

Megaloencephalic leukoencephalopathy (spongiform leukoencephalopathy or van der Knaap disease) is an autosomal-recessive, neurodegenerative disorder with macrocephaly in the first year of life but delayed onset

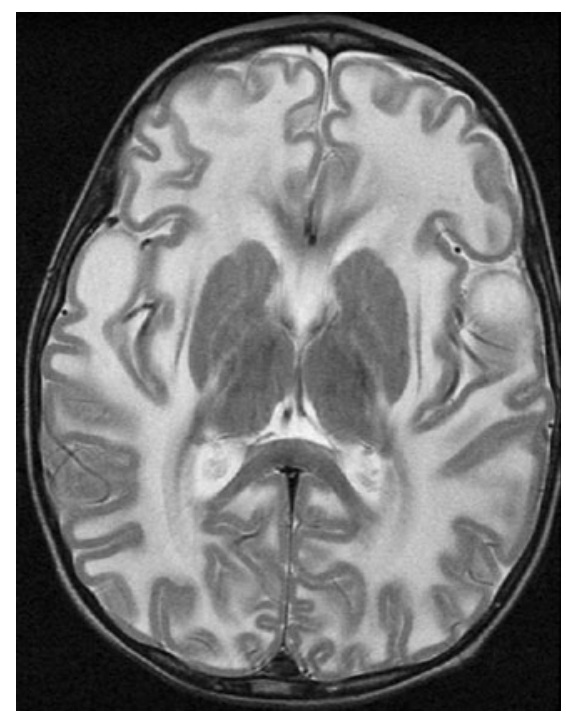

Fig. 1 Axial T2-W image

A. Malhotra $(\bowtie) \cdot$ P.-L. Westesson

Department of Radiology, Division of Neuroradiology,

University of Rochester Medical Center,

601 Elmwood Ave., P. O. Box 648, Rochester, NY 14642, USA

e-mail: ajayradiology@yahoo.com

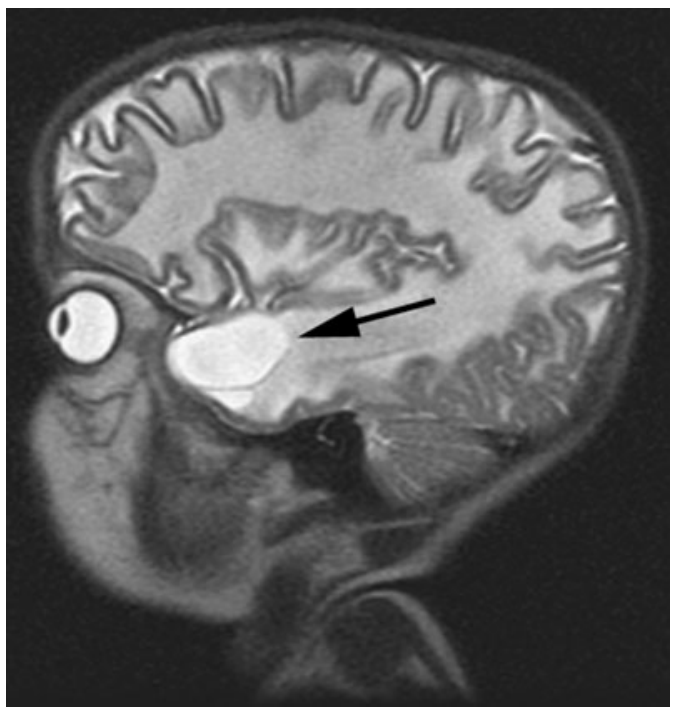

Fig. 2 Sagittal T2-W image

of motor deterioration and cognitive decline despite markedly abnormal MR imaging findings [1]. There is diffuse, symmetric white matter involvement with subcortical cyst formation in the anterior temporal and frontoparietal regions. The imaging and clinical features are progressive in all cases. The presence of subcortical cysts and only subtle cerebellar involvement help distinguish it from vanishing white matter disease [2].

\section{References}

1. Schiffmann R, van der Knaap MS (2009) Invited article: an MRIbased approach to the diagnosis of white matter disorders. Neurology 72:750-759

2. van der Knaap MS, Barth PG, Stroink H et al (1995) Leukoencephalopathy with swelling and a discrepantly mild clinical course in eight children. Ann Neurol 37:324-334 